Check for updates

Cite this: RSC Adv., 2019, 9, 10091

\title{
Synthesis of 5-aminolevulinic acid with nontoxic regents and renewable methyl levulinate $\uparrow$
}

\author{
Yuxia Zai, ${ }^{a}$ Yunchao Feng, ${ }^{a}$ Xianhai Zeng, (D) *abc Xing Tang, (D) abc Yong Sun ${ }^{\text {abc }}$ \\ and Lu Lin ${ }^{\text {abc }}$
}

Received 28th February 2019

Accepted 20th March 2019

Synthesis of 5-aminolevulinic acid (5-ALA) was presented with novel bromination of biobased methyl levulinate $(\mathrm{ML})$, followed by ammoniation and hydrolysis. Copper bromide $\left(\mathrm{CuBr}_{2}\right)$ was employed as the bromination reagent with higher selectivity and activity instead of the conventional liquid bromine $\left(\mathrm{Br}_{2}\right)$. 5-ALA was obtained in a high yield (64\%) and purity ( $>95 \%$ ) by optimum design, which is of great potential in industrialization.

DOI: 10.1039/c9ra01517e

rsc.li/rsc-advances

5-Aminolevulinic acid (5-ALA) is generally known as an essential precursor molecule for tetrapyrrole synthesis such as porphyrin, heme, chlorophyll and vitamin B12. ${ }^{1}$ It has been widely applied in localizing and photodynamic therapy for various cancers. ${ }^{2-4}$ It has also been used as a selective biodegradable insecticide, herbicide, salt tolerance agent or plant growth regulator in agricultural fields. ${ }^{5}$

To date, 5-ALA was mainly synthesized by microbial production methods, ${ }^{6}$ but the long-time and high-cost course restrict its scaled applications. On the other side, chemical routes using 2hydroxypyridine, tetrahydrofurfurylamine and furfurylamine as starting materials involved in numerous bottleneck including toxic intermediates and rigorous reaction conditions. ${ }^{7,8}$ Thus, to develop a new pathway for 5-ALA production is of great significance, especially one that is a green and sustainable.

Biomass is an appealing starting material in value-added chemicals synthesis because of its advantages of renewability, sustainability and availability. ${ }^{9}$ Several biomass-derived platform compounds such as 5-hydroxymethylfurfural (HMF), 5chloromethylfurfural (CMF), levulinic acid (LA) or its esters have been reported as efficient raw materials in the production of 5-ALA. ${ }^{10,11}$ However, the industrial manufacture of furan-type HMF and CMF cannot currently be achieved easily due to the high production and environment costs. ${ }^{12,13}$ Furthermore, conversion of furan-type chemicals to 5-ALA also suffers the economic problems concerning the use of expensive oxidants in the ring-opening stage. Unlike CMF and HMF, LA and its esters can be easily produced both from hemicellulose and cellulose, and its yearly tonnage is therefore available via the acidic

${ }^{a}$ College of Energy, Xiamen University, Xiamen 361102, China. E-mail: xianhai.zeng@ xтu.edu.cn; Fax: +86-592-2880701; Tel: +86-592-2880701

${ }^{b}$ Fujian Engineering and Research Centre of Clean and High-valued Technologies for Biomass, Xiamen 361102, China

'Xiamen Key Laboratory of Clean and High-valued Utilization for Biomass, Xiamen 361102, China

$\dagger$ Electronic supplementary information (ESI) available. See DOI: 10.1039/c9ra01517e processing of biomass at a competitively low price. ${ }^{14-16}$ Thus, to synthesize 5-ALA from LA or its esters is exceptionally promising. Typically, 5-ALA can be effectively prepared from levulinates via a three-stage process including bromination, ammoniation and acidolysis. ${ }^{17}$ However, the bromination of levulinates with $\mathrm{Br}_{2}$ in this course has low selectivity to 5-bromo derivatives. Besides, $\mathrm{Br}_{2}$ is hazardous and environmentally unfriendly. Hence, a crucial step of the production of 5-ALA from levulinates is to explore a safe bromide agent with higher selectivity and activity.

$\mathrm{CuBr}_{2}$, a green and low toxic brominated reagent, was usually used for the synthesis of $\alpha$-bromination of cyclopentenone derivatives and its closest analogues-indanone of carbonyl compounds for its advantages of short reaction times, high selectivity of the products, high yields and easily handle procedures. ${ }^{18,19}$ In this content, various unsymmetrical aliphatic ketones including levulinic acid, methyl levulinate, ethyl levulinate, 5-hydroxy-2-pentanone and 2-butanone was attempted for bromizing with $\mathrm{CuBr}_{2}$ (Table 1). Interestingly, the yields of bromination products were different, depending on the source of aliphatic ketones.

In this work, we present the synthesis of 5-ALA from biomass derived methyl levulinate (ML) under mild conditions using $\mathrm{CuBr}_{2}$ as a greener bromine donor, and a high yield of 5-bromolevulinate (M5B) up to $85 \%$ was achieved. Furthermore, a detailed discussion of ammoniation and acidolysis was also presented, corresponding a high total 5-ALA yield over $64 \%$ (Scheme 1).

The first attempt to screen the reaction conditions for the bromination of ML with $\mathrm{CuBr}_{2}$ are shown in Table 2. An encouraging yield of the desired product $(50 \%)$ is indeed obtained using $\mathrm{CuBr}_{2}$ as bromide agent in $\mathrm{CH}_{3} \mathrm{OH}$ at $40{ }^{\circ} \mathrm{C}$ for $3 \mathrm{~h}$ (Table 2, entry 1). The investigation of the solvent indicated that $\mathrm{CH}_{3} \mathrm{OH}-\mathrm{CHCl}_{3}$ mixed solvent was superior to ethyl acetate (EA), $\mathrm{CHCl}_{3}, \mathrm{CH}_{3} \mathrm{OH}, \mathrm{CH}_{3} \mathrm{OH}-\mathrm{EA}$ and EA-CHCl (Table 2, entry 2-6). The results may due to the fact that $\mathrm{CH}_{3} \mathrm{OH}$ can improve the selectivity of $\mathrm{M} 5 \mathrm{~B}$ and haloalkanes are favourable to 
Table 1 The bromination of aliphatic ketones with $\mathrm{CuBr}_{2}{ }^{a}$<smiles>[R]C(=O)CCCC(C)C(C)C(C)=O</smiles><smiles>CCOC(=O)CCC(=O)CBr</smiles><smiles>CCCC(=O)CBr</smiles>

${ }^{a}$ Reaction condition: compounds $=2.5 \mathrm{mmol}, \mathrm{CuBr}_{2}=1.67 \mathrm{~g}$, solvent $=30 \mathrm{~mL}$, temperature $=40^{\circ} \mathrm{C}$, time $=4 \mathrm{~h}$.

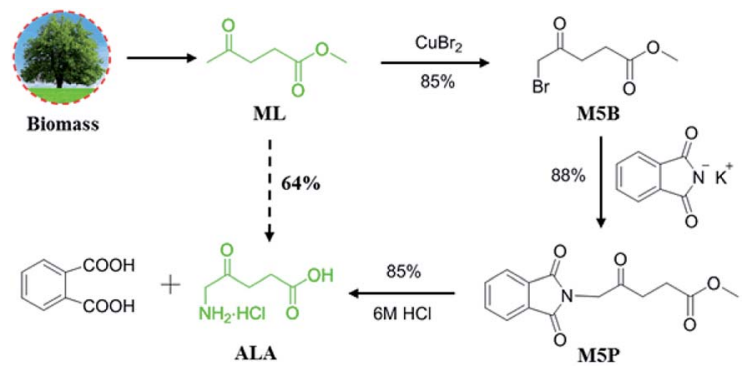

Scheme 1 Synthesis of 5-ALA from ML.

Table 2 The bromination of $M L$ to ${\mathrm{M} 5 \mathrm{~B}^{a}}^{a}$

\begin{tabular}{|c|c|c|c|}
\hline Entry & Bromine source & Solvent & M5B yield (\%) \\
\hline 1 & $\mathrm{CuBr}_{2}$ & $\mathrm{CH}_{3} \mathrm{OH}$ & 50 \\
\hline 2 & $\mathrm{CuBr}_{2}$ & $\mathrm{CHCl}_{3}$ & 7 \\
\hline 3 & $\mathrm{CuBr}_{2}$ & EA & 13 \\
\hline 4 & $\mathrm{CuBr}_{2}$ & $\mathrm{CH}_{3} \mathrm{OH} / \mathrm{EA}(1: 1)$ & 32 \\
\hline 5 & $\mathrm{CuBr}_{2}$ & $\mathrm{CHCl}_{3} / \mathrm{EA}(1: 1)$ & 14 \\
\hline 6 & $\mathrm{CuBr}_{2}$ & $\mathrm{CH}_{3} \mathrm{OH} / \mathrm{CHCl}_{3}(1: 1)$ & 80 \\
\hline 7 & $\mathrm{CuBr}_{2}$ & $\mathrm{CH}_{3} \mathrm{OH} / \mathrm{CHCl}_{3}(4: 1)$ & 56 \\
\hline 8 & $\mathrm{CuBr}_{2}$ & $\mathrm{CH}_{3} \mathrm{OH} / \mathrm{CHCl}_{3}(3: 1)$ & 75 \\
\hline 9 & $\mathrm{CuBr}_{2}$ & $\mathrm{CH}_{3} \mathrm{OH} / \mathrm{CHCl}_{3}(1: 3)$ & 74 \\
\hline 10 & $\mathrm{CuBr}_{2}$ & $\mathrm{CH}_{3} \mathrm{OH} / \mathrm{CHCl}_{3}(1: 4)$ & 66 \\
\hline $11^{b}$ & $\mathrm{ZnBr}_{2}$ & $\mathrm{CH}_{3} \mathrm{OH} / \mathrm{CHCl}_{3}(1: 1)$ & 0 \\
\hline $12^{b}$ & $\mathrm{MgBr}_{2}$ & $\mathrm{CH}_{3} \mathrm{OH} / \mathrm{CHCl}_{3}(1: 1)$ & 0 \\
\hline $13^{b}$ & $\mathrm{AlBr}_{3}$ & $\mathrm{CH}_{3} \mathrm{OH} / \mathrm{CHCl}_{3}(1: 1)$ & 0 \\
\hline 14 & $\mathrm{Br}_{2}$ & $\mathrm{CH}_{3} \mathrm{OH} / \mathrm{CHCl}_{3}(1: 1)$ & 55 \\
\hline 15 & $2 \mathrm{C}_{4} \mathrm{H}_{9} \mathrm{NOHBr} \cdot \mathrm{Br}_{2}$ & $\mathrm{CH}_{3} \mathrm{OH} / \mathrm{CHCl}_{3}(1: 1)$ & 40 \\
\hline 16 & $\mathrm{NBS}+\mathrm{BPO}$ & $\mathrm{CH}_{3} \mathrm{OH} / \mathrm{CHCl}_{3}(1: 1)$ & 28 \\
\hline 17 & $\mathrm{NBS}+\mathrm{AIBN}$ & $\mathrm{CH}_{3} \mathrm{OH} / \mathrm{CHCl}_{3}(1: 1)$ & 18 \\
\hline
\end{tabular}

${ }^{a}$ Reaction condition: $\mathrm{ML}=0.33 \mathrm{~g}$, bromine source $=3$ mole of $\mathrm{ML}$, solvent $=30 \mathrm{~mL}$, temperature $=40{ }^{\circ} \mathrm{C}$, time $=3 \mathrm{~h} .{ }^{b}$ Time $=24 \mathrm{~h}$.

halogenation. ${ }^{\mathbf{1 3 , 2 0 , 2 1}}$ Based on the above, changing the volume ratio of $\mathrm{CH}_{3} \mathrm{OH}$ to $\mathrm{CHCl}_{3}$ (Table 2, entry 6-10), improved the yield of M5B to $80 \%$ (Table 2, entry 6). We then proceeded to evaluate various metal bromides, including $\mathrm{ZnBr}_{2}, \mathrm{MgBr}_{2}$, and $\mathrm{AlBr}_{3}$ under the identical conditions. However, no conversion was detected even after $24 \mathrm{~h}$ (Table 2, entry 11-13). These metal bromides were also found to be inactive in bromination as noted in previous studies. ${ }^{22,23}$ The conventional bromination agent such as $\mathrm{Br}_{2}, 2 \mathrm{C}_{4} \mathrm{H}_{9} \mathrm{NOHBr} \cdot \mathrm{Br}_{2}$ and NBS can obviously improve the reaction (Table 2, entry 14-17), although they were lower than that achieved with $\mathrm{CuBr}_{2}$ (Table 2, entry 6). Experiments that screened for the bromine donors suggested that $\mathrm{CuBr}_{2}$ was the most effective for the bromination of ML (Table 2, entry 6). Note that a detailed study of the reaction conditions were discussed (Tables S1, S2 and Fig. S1 $\dagger$ ), and a high M5B yield over $85 \%$ was obtained at $40{ }^{\circ} \mathrm{C}$ for $5 \mathrm{~h}$ (detected by GC-MS, Fig. S3 $\dagger$ ).

As shown in Fig. 1, XRD patterns indicated that $\mathrm{CuBr}_{2}$ was transformed into CuBr (PDF\#06-0292) after the reaction. When TEMPO and 2,6-di-tert-butyl-4-methylphenol (BHT) were introduced to eliminate free radical, no M5B was detected. Based on these results, a mechanism for the current bromination process was proposed, as shown in Scheme 2. Initially, Lewis acidity of $\mathrm{CuBr}_{2}$ promoted the transformation from carbonyl keto to copper-bound enolate at the $\alpha$-position. ${ }^{24}$ Subsequently, the hemolysis of enolate to get ethenyloxy radical, and the reactive group reacts with $\mathrm{CuBr}_{2}$ to generate an M5B along with an equivalent of $\mathrm{CuBr}$.

Intensive efforts have been devoted to introduce the key amino group on M5B. ${ }^{17,25-27}$ Among them, a typical Gabriel reaction using potassium phthalimide (KPI) as ammonia resource has a promising commercial availability, however, only a moderate M5P yield of $59 \%$ was achieved at $110{ }^{\circ} \mathrm{C}$ for $12 \mathrm{~h}^{27}$ In this work, optimizing the experimental conditions of Gabriel reaction including reaction time, temperature, the amount of solvent and the molar ratio of KPI to M5B (Tables S3 and S4 $\dagger$ ) was subsequently conducted, and a maximum M5P yield of $88 \%$ was obtained at $40{ }^{\circ} \mathrm{C}$ for only $4 \mathrm{~h}$ (detected by GC-MS, Fig. S4 $\dagger$ ). This significant improvement is no doubt accelerate the practical application of 5-ALA. Finally, an acid hydrolysis process was applied with $6 \mathrm{M} \mathrm{HCl}$ (Fig. S2 $\dagger$ ). The obtained products were concentrated in vacuum at $40{ }^{\circ} \mathrm{C}$ to avoid the polymerization of 5 -ALA at high temperatures, ${ }^{13}$ affording a satisfied 5-ALA yield of 85\% (Fig. S11 and 12†) (determined by HPLC, Fig. S5 $\dagger$ ).

In summary, we have developed a new efficient bromination method for the conversion of biomass derived ML to 5-ALA,

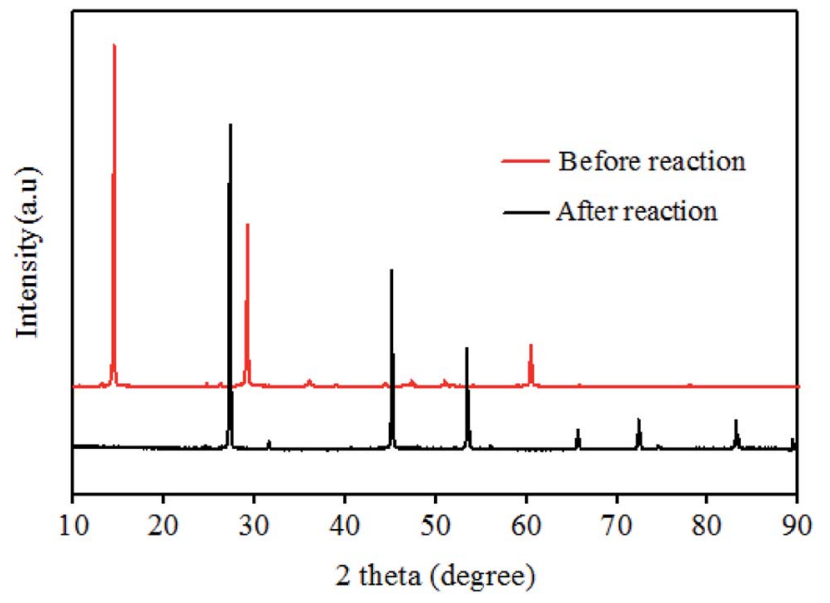

Fig. 1 XRD pattern of catalyst. 


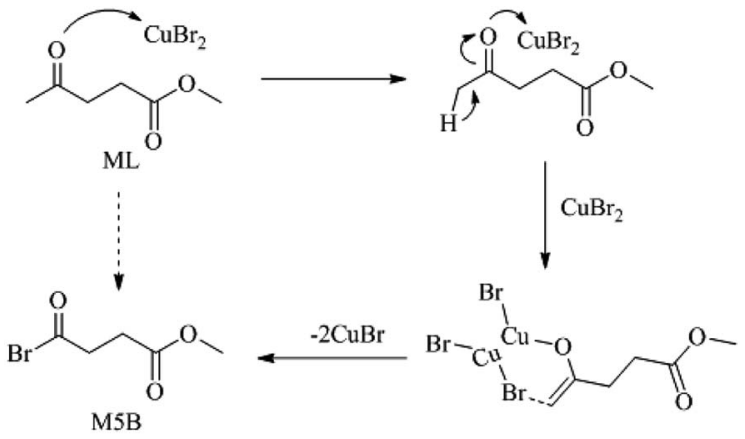

Scheme 2 The proposed mechanism of conversion of ML to M5B with $\mathrm{CuBr}_{2}$.

a key chemical that has been widely applied in medical and agricultural areas. $\mathrm{CuBr}_{2}$ was applied as both catalyst and bromine atom donor and was demonstrated to be of higher selectivity and activity than the conventional hazardous $\mathrm{Br}_{2}$ in ML bromination. Each stage proceeds in high ( $\sim 85 \%)$ yield and affords 5-ALA in 95\% purity, giving a process that could be commercially viable.

\section{Conflicts of interest}

There are no conflicts to declare.

\section{Acknowledgements}

We thank for the financial support from the National Natural Science Foundation of China (Grant No. 21506177; 21676223), the Fundamental Research Funds for the Central Universities (Grant No. 20720160087; 20720160077; 20720170062), and the Energy Development Foundation of the College of Energy, Xiamen University (No. 2017NYFZ02).

\section{Notes and references}

1 K. Sasaki, M. Watanabe, T. Tanaka and T. Tanaka, Appl. Microbiol. Biotechnol., 2002, 58, 23-29.

2 M. C. Tetard, M. Vermandel, S. Mordon and J. P. Lejeune, Photodiagn. Photodyn. Ther., 2014, 11, 319-330.

3 T. Ishikawa, Y. Kajimoto, Y. Inoue, Y. Ikegami and T. Kuroiwa, Adv. Cancer Res., 2015, 125, 197.

4 H. Fukuda, A. Casas and A. Batlle, Int. J. Biochem. Cell Biol., 2005, 37, 272-276.

5 Z. J. Zhang, H. Z. Li, W. J. Zhou, Y. Takeuchi and K. Yoneyama, Plant Growth Regul., 2006, 49, 27-34.

6 S. L. Liu, G. M. Zhang, X. K. Li and J. Zhang, Appl. Microbiol. Biotechnol., 2014, 98, 7349-7357.
7 H. Kawakami, T. Ebata and H. Matsushita, Agric. Biol. Chem., 1991, 55, 1687-1688.

8 H. Takeya, H. Ueki, S. Miyanari, T. Shimizu and M. Kojima, J. Photochem. Photobiol., A, 1996, 94, 167-171.

9 A. Corma, S. Iborra and A. Velty, Chem. Rev., 2007, 107, 24112502.

10 M. Mascal and S. Dutta, Green Chem., 2010, 13, 40-41.

11 L. Cottier, G. Descotes, L. Eymard and K. Rapp, Cheminform, 1995, 303-306.

12 R. J. van Putten, J. C. van der Waal, E. de Jong, C. B. Rasrendra, H. J. Heeres and J. G. de Vries, Chem. Rev., 2013, 113, 1499-1597.

13 M. Mascal, ChemSusChem, 2015, 8, 3391-3395.

14 S. G. Wettstein, D. M. Alonso, E. I. Gurbuz and J. A. Dumesic, Curr. Opin. Chem. Eng., 2012, 1, 218-224.

15 D. M. Alonso, J. Q. Bond and J. A. Dumesic, Green Chem., 2010, 12, 1493-1513.

16 D. J. Hayes, S. Fitzpatrick, M. H. B. Hayes and J. R. H. Ross, The Biofine Process - Production of Levulinic Acid, Furfural, and Formic Acid from Lignocellulosic Feedstocks, Wiley-VCH Verlag GmbH \& Co., 2008, pp. 139-164.

17 H. J. Ha, S. K. Lee, Y. J. Ha and J. W. Park, Synth. Commun., 1994, 24, 2557-2562.

18 V. Z. Shirinian, D. V. Lonshakov, V. V. Kachala, I. V. Zavarzin, A. A. Shimkin, A. G. Lvov and M. K. Mikhail, Regio- and chemoselective bromination of 2,3-diarylcyclopent-2-en-1ones, J. Org. Chem., 2012, 77, 8112-8123.

19 R. H. Vekariya and H. D. Patel, Synthesis of a-bromocarbonyl compounds: recent advances, Tetrahedron, 2014, 70, 39493961.

20 L. Moens, Synthesis of $\delta$-Aminolevulinic Acid, ACS Symp. Ser., 2001, 784, 37-50.

21 D. R. Lane, M. Mascal and P. Stroeve, Renewable Energy, 2016, 85, 994-1001.

22 T. Liu, J. Sun, Q. Wang, L. Li and M. D. Zhou, Eur. J. Org. Chem., 2017, 2017, 1915-1921.

23 M. Y. Zhou, S. S. Kong, L. Q. Zhang, M. Zhao, J. A. Duan, Z. Ou-Yang and M. Wang, Tetrahedron Lett., 2013, 54, 3962-3964.

24 R. W. Evans, J. R. Zbieg, S. Zhu, W. Li and D. W. C. Macmillan, J. Am. Chem. Soc., 2013, 135, 1607416077.

25 L. Moens, US005907058A, Lakewood and Colo, 1999.

26 L. Moens, US006583317B1, Lakewood and Colo, 2003.

27 J. J. Bozell, L. Moens, D. C. Elliott, Y. Wang, G. G. Neuenscwander, S. W. Fitzpatrick, R. J. Bilski and J. L. Jarnefeld, Resour., Conserv. Recycl., 2000, 28, 227-239. 